University of Montana

ScholarWorks at University of Montana

\title{
Biotic Resistance Via Granivory: Establishment by Invasive, Naturalized, and Native Asters Reflects Generalist Preference
}

\author{
Dean E. Pearson \\ Ragan M. Callaway \\ University of Montana - Missoula, Ray.Callaway@mso.umt.edu \\ John L. Maron \\ University of Montana - Missoula, john.maron@mso.umt.edu
}

Follow this and additional works at: https://scholarworks.umt.edu/biosci_pubs

Part of the Biology Commons

Let us know how access to this document benefits you.

\section{Recommended Citation}

Pearson, Dean E.; Callaway, Ragan M.; and Maron, John L., "Biotic Resistance Via Granivory:

Establishment by Invasive, Naturalized, and Native Asters Reflects Generalist Preference" (2011).

Biological Sciences Faculty Publications. 249.

https://scholarworks.umt.edu/biosci_pubs/249

This Article is brought to you for free and open access by the Biological Sciences at ScholarWorks at University of Montana. It has been accepted for inclusion in Biological Sciences Faculty Publications by an authorized administrator of ScholarWorks at University of Montana. For more information, please contact scholarworks@mso.umt.edu. 


\title{
Biotic resistance via granivory: establishment by invasive, naturalized, and native asters reflects generalist preference
}

\author{
Dean E. Pearson, ${ }^{1,2,3}$ Ragan M. Callaway, ${ }^{2}$ and John L. Maron ${ }^{2}$ \\ ${ }^{1}$ Rocky Mountain Research Station, U.S.D.A. Forest Service, Missoula, Montana 59801 USA \\ ${ }^{2}$ Division of Biological Sciences, University of Montana, Missoula, Montana 59812 USA
}

\begin{abstract}
Escape from specialist natural enemies is frequently invoked to explain exotic plant invasions, but little attention has been paid to how generalist consumers in the recipient range may influence invasion. We examined how seed preferences of the widespread generalist granivore Peromyscus maniculatus related to recruitment of the strongly invasive exotic Centaurea stoebe and several weakly invasive exotics and natives by conducting laboratory feeding trials and seed addition experiments in the field. Laboratory feeding trials showed that $P$. maniculatus avoided consuming seeds of $C$. stoebe relative to the 12 other species tested, even when seeds of alternative species were $53-94 \%$ smaller than those of $C$. stoebe. Seed addition experiments conducted in and out of rodent exclosures revealed that weakly invasive exotics experienced relatively greater release from seed predation than C. stoebe, although this was not the case for natives. Seed mass explained $81 \%$ of the variation in recruitment associated with rodent exclusion for natives and weak invaders, with larger-seeded species benefiting most from protection from granivores. However, recruitment of C. stoebe was unaffected by rodent exclusion, even though the regression model predicted seeds of correspondingly large mass should experience substantial predation. These combined laboratory and field results suggest that generalist granivores can be an important biological filter in plant communities and that species-specific seed attributes that determine seed predation may help to explain variation in native plant recruitment and the success of exotic species invasions.
\end{abstract}

Key words: biotic resistance; Centaurea maculosa; Centaurea stoebe; chemical defense; feeding trials; Peromyscus maniculatus; recruitment; seed addition; seed mass; seed predation.

\section{INTRODUCTION}

The explosive success of many exotic organisms in their introduced ranges is an enigma that has puzzled ecologists since Darwin (1859) and Elton (1958). As Elton noted, given favorable abiotic conditions, there are various forms of biotic resistance that constitute the critical filters invaders must overcome. Correspondingly, the failure of exotic organisms to establish, and the limited success of most exotic organisms that do establish, is commonly attributed to "biotic resistance" (Elton 1958, Mack 1996, Williamson and Fitter 1996, Levine et al. 2004). Biotic filters with the potential to resist or impede exotic invasion include competition from natives, attack by native consumers or pathogens, and the absence of suitable native mutualists. However, studies of exotic plant invasions have largely focused on biotic resistance arising from competition, and in particular, how native plant diversity influences invasibility (Levine et al. 2004). Biotic resistance from generalist consumers has received relatively little attention, perhaps in part because generalists occur in both

Manuscript received 28 January 2011; revised and accepted 2 May 2011. Corresponding Editor: P. M. Kotanen.

${ }^{3}$ E-mail: dpearson@fs.fed.us the native and recipient ranges, and the assumption has been that generalist consumer pressure should be comparable between ranges (but see Keane and Crawley 2002, Parker et al. 2006, Schaffner et al. 2011).

Biotic resistance from generalist consumers, however, has the potential to be substantial. Although generalist herbivores incorporate a range of foods in their diets, they also exhibit strong preferences that can profoundly affect the composition and diversity of native plant communities (Brown and Heske 1990, Howe et al. 2006). Thus it is reasonable to assume that native generalists may similarly influence invasion success of exotics. Many generalists readily attack certain exotics (Mack 1996, Maron and Vilá 2001, Keane and Crawley 2002, Parker et al. 2006) while avoiding others (Cappuccino and Carpenter 2005, Parker et al. 2006, Schaffner et al. 2011), thereby potentially contributing to outcomes of invasion. Yet our understanding of when and how generalist consumers contribute to biotic resistance remains limited.

One class of generalist consumers that may greatly influence invasion success is granivorous rodents. Native generalist rodent seed predators can have important impacts on native plants by suppressing seedling recruitment (Reader 1993, Ostfeld et al. 1997, Orrock et al. 2008, Pearson and Callaway 2008, Zwolak et al. 
2010), reducing adult plant populations (Maron and Kauffman 2006, Bricker et al. 2010), and even restructuring plant communities through selective foraging (Davidson et al. 1984, Brown and Heske 1990). Given these strong impacts on populations and communities of native plants, native rodents clearly have great potential to influence invasion dynamics as well. As a case in point, the exotic perennial grass Eragrostis lehmanniana and the exotic annual forb Erodium cicutarium increased dramatically in the classic long-term rodent exclusion studies in Arizona (Davidson et al. 1984, Brown and Heske 1990). Since plants are commonly seed limited (Clark et al. 2007) and seed limitation should be particularly important for newly establishing populations of invaders, seed predation has the potential to be a particularly strong form of biotic resistance (Maron and Vilá 2001).

Several studies have quantified how predation rates on exotic seeds vary depending on habitat (Vilá and Gimeno 2003, Swope and Parker 2010), postdispersal seed predator guilds (Carrillo-Gavilán et al. 2010), or both (Alba-Lynn and Henk 2010). Moreover, research has shown that exotic plants can indirectly affect native plants via apparent competition mediated by rodent seed predators (Orrock et al. 2008, Pearson and Callaway 2008, Dangremond et al. 2010). However, surprisingly few studies have explicitly compared seed predation between natives and exotics (Blaney and Kotanen 2001, Shahid et al. 2009) or, more importantly, explored how variation in postdispersal seed predation between natives and exotics influences the magnitude of seedling recruitment (Nunez et al. 2008). One important attribute of seeds that can critically influence their vulnerability to granivorous rodents is size. Larger seeds of herbaceous plants are commonly more at risk to rodent consumers than are smaller seeds (Mittlebach and Gross 1984, Brown and Heske 1990, Reader 1993, Blaney and Kotanen 2001, Pearson and Callaway 2008, but see Carrillo-Gavilán et al. 2010). This idea predicts that large-seeded exotic species may experience greater biotic resistance in recipient communities than smallerseeded species, although we know of no explicit test of this prediction. In fact, no studies have explicitly quantified seed preferences by granivorous rodents and experimentally integrated these preferences to understand patterns of plant recruitment and community composition in the field.

Here we explore the impacts of a native seed predator, the deer mouse, Peromyscus maniculatus, the most widely distributed rodent granivore in North America (Wilson and Ruff 1999), on a suite of exotic and native species in the family Asteraceae (see Plate 1). We conducted laboratory feeding trials to evaluate seed preference by $P$. maniculatus for the strongly invasive exotic aster, spotted knapweed (Centaurea stoebe, formerly C. maculosa) vs. several naturalized or weakly invasive exotic (sensu Ortega and Pearson 2005) and native species. We then examined how strongly feeding trial results translate to patterns observed in the field by experimentally determining how rodent exclusion influenced seedling establishment for a subset of these species. We hypothesized that if seed predation was an important form of biotic resistance in this system, $P$. maniculatus would prefer seeds of native plants and weakly invasive exotics over the strong invader, and that this preferential feeding would translate into higher relative recruitment rates for the strong invader in the field.

\section{Methods}

We determined $P$. maniculatus seed preferences by contrasting the strong invader $C$. stoebe with four weakly invasive exotic species and eight native species (Appendix) in laboratory feeding trials. We then examined how seed predation affected recruitment for a subset of these species using field experiments in intermountain grasslands of western Montana. Peromyscus maniculatus (see Plate 1) is a generalist rodent in terms of its habitat and diet and is widely distributed across North America (Wilson and Ruff 1999). It is one of the single most important seed predators in North America, having been implicated in suppression of a range of native and exotic plant species in our system (Pearson and Callaway 2008, Bricker et al. 2010, Zwolak et al. 2010) and other systems across the continent (Mittlebach and Gross 1984, Maron and Kauffman 2006, Orrock et al. 2008, Dangremond et al. 2010). Centaurea stoebe is one of the most widespread and highly invasive exotic plants in the intermountain regions of western North America (Sheley et al. 1998). It is listed as a noxious weed in Montana (available online $)^{4}$ where it achieves high local densities in natural vegetation communities and displaces native plants (Ortega and Pearson 2005). Thus it is of great interest to understand factors that contribute to the success of $C$. stoebe. At the same time, it is useful to determine whether biotic resistance by $P$. maniculatus might help explain the limited success of other exotic species. The four other exotics (Appendix) are all widespread in Montana, but none occur at high local densities (e.g., Ortega and Pearson 2005) and none are classified as noxious weeds in the state (see footnote 1). Based on documented levels of abundance and impact, we considered $C$. stoebe as a strong invader and the other four exotics as weak invaders, consistent with other studies (Mitchell and Power 2003, Cappuccino and Carpenter 2005, Ortega and Pearson 2005). As a contrast for examining the impacts of $P$. maniculatus on exotic species, we chose eight native species that represent a gradient of seed size bracketing the size of $C$. stoebe seeds. This contrast of strong and weak invaders and native species is consistent with a recent framework proposed for advancing studies of biological invasions

\footnotetext{
${ }^{4}\langle$ http://invader.dbs.umt.edu/Noxious_Weeds/〉
} 


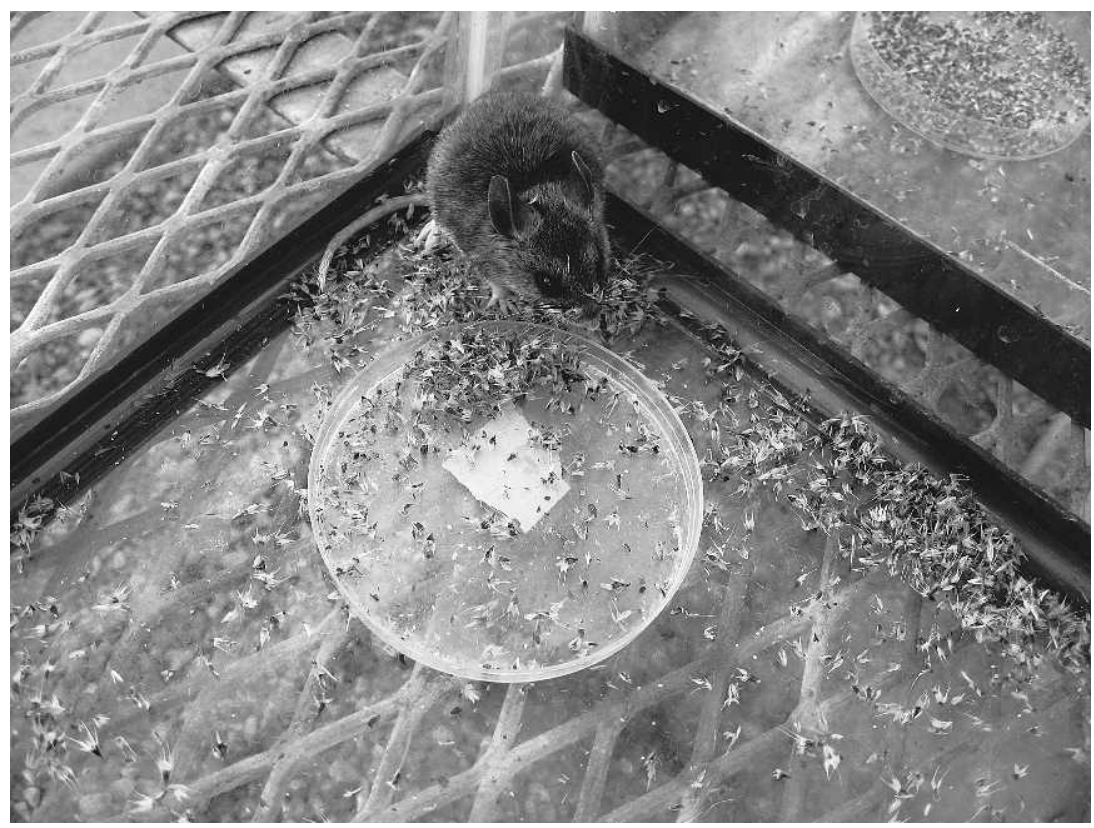

Plate 1. A deer mouse (Peromyscus maniculatus) sitting in a feeding trial arena amid the leftover seed coats and seeds of a native aster. Photo credit: Warren Hansen.

(van Kleunen et al. 2010). To control for evolutionary history, all species are in the Asteraceae except for Pseudoroegneria spicata, which is the dominant native grass (Poaceae) over much of this region.

\section{Laboratory feeding trials}

We conducted cafeteria-style feeding trials in 37.8-L (10-gallon) glass aquaria with wire mesh tops to examine how $P$. maniculatus varied in its seed feeding preferences. The tanks were divided into two square halves by a 3.8 $\mathrm{cm}$ tall by $2 \mathrm{~mm}$ wide clear plastic strip form fit and glued to the bottom and sides of the tank. The divider minimized mixing of the different species of seeds, but allowed mice to readily move back and forth between the two sides of the arena by climbing over the partition. A nest box was constructed from a small polyvinyl chloride (PVC) tube $(5.1 \mathrm{~cm}$ in diameter by $7.6 \mathrm{~cm}$ in length) glued to the side of the tank $6.4 \mathrm{~cm}$ above the tank bottom and centered over the divider. This created a neutral start and return point for mouse foraging bouts. Water was provided ad libitum in a $300-\mathrm{mL}$ watering bottle attached to the tank directly above the divider opposite the nest box (also in a neutral location). Experimental trials were conducted in a greenhouse under ambient light conditions during late summer and fall in 2009 and 2010.

In each trial, we assessed deer mouse foraging preferences for $C$. stoebe seeds relative to seeds of another exotic or native species. Three grams of seeds were placed in each of two petri dishes $(10 \mathrm{~cm}$ in diameter) and set on either side of the divider. Preliminary trials indicated $3 \mathrm{~g}$ of seeds was sufficient to ensure that dishes were not emptied of seeds overnight. Seed masses were determined using dry mass in a laboratory at $70^{\circ} \mathrm{F}$. Stable masses were ensured by weighing seeds over 24-48 hours until masses stabilized. Seed species were randomly assigned to either side of the arena. The exception to the above methods was one three-way seed offering of $C$. stoebe, Balsamorhiza sagittata, and $P$. spicata. This group was chosen to examine how laboratory seed preferences related to a prior field study where $P$. maniculatus differentially suppressed the natives (Pearson and Callaway 2008). In this scenario, the arena had no partition and seeds were offered at equal distances from a central nest box. All seeds for feeding trials were purchased from regional suppliers except for the exotic species, which were collected locally.

All P. maniculatus were wild adult mice caught in grassland and open forest habitats in the Missoula valley. We captured mice using Sherman live traps baited with peanut butter and rolled oats. Traps were checked each morning around 07:00 hours, and mice were brought in from the field and offered fresh apple slices and oats until $\sim$ 12:00 hours, when all food was removed. Mice were introduced into experimental arenas around 19:00 hours on the evening of the day they were captured, and they were allowed to become accustomed to their surroundings for $\sim 15$ minutes before the seeds were placed in the arenas. Mice had generally settled into the nest box prior to running each trial. Mice were removed from arenas at 07:00 hours the following morning and released at their capture sites. Each species-combination trial was repeated 5-20 times using unique mice for each trial. To avoid re-using mice, each was marked by clipping a patch of hair from their 
right hip before release. All human safety and animal handling protocols were vetted by the University of Montana Institutional Animal Care and Use Committee.

The seed masses of the species we used in feeding trials ranged over two orders of magnitude from 0.0001 to $0.01 \mathrm{~g}$. This range of seed sizes ensured that we could run feeding trials in which seeds of contrasted species were either smaller or larger than those of $C$. stoebe (Appendix). However, there is one problem with comparing preferences between seeds of different sizes based on the mass of remaining total residual materials. The ratio of inedible seed parts (seed coat and pappus) to edible seed parts (endosperm and embryo) generally increases as seed size declines, due to surface area to volume relationships. This has the potential for creating a bias, since even if there were no preferences based on size, one would expect more residual materials remaining from consumption of small vs. large seeds. To address this problem, we used two methods to examine residual materials from the feeding trials. In trials where C. stoebe was offered against species with relatively large seeds (mean mass $>0.001 \mathrm{~g}$ ), we weighed the total residual mass for each species following the trials and used these direct measurements to calculate the total mass consumed. In trials where $C$. stoebe was offered against a species with a mean mass $\leq 0.001 \mathrm{~g}$, we counted all undamaged seeds in one $1.2 \mathrm{~cm}^{3}$ volume subsample from the total residuals for each species and used this to estimate the total seed mass consumed.

\section{Seed addition experiments}

In the field, we examined the effect of P. maniculatus seed predation on plant recruitment for a subset of native and exotic species that were used in the feeding trials and commonly occur in our study area (Appendix). Here, we explicitly chose species that varied in seed size, so we could explore how variation in seed size predicted how strongly seed predation suppressed recruitment. We cleared vegetation from all seed addition subplots prior to treatment so we could examine postdispersal seed predation effects on plant establishment in the absence of plant competition. At 10 sites located in rough fescue (Festuca scabrella) dominated grasslands and spread over a $500-\mathrm{km}^{2}$ area in the Blackfoot Valley in western Montana, we established one $10 \times 10 \mathrm{~m}$ rodent exclusion plot and an equal-sized paired, unfenced control plot that was $\sim 10 \mathrm{~m}$ away. Rodent exclosures were constructed of $0.625 \times 0.625 \mathrm{~cm}$ wire mesh fencing buried $40 \mathrm{~cm}$ and extending $60 \mathrm{~cm}$ aboveground. Fences were topped with $20 \mathrm{~cm}$ of solid metal flashing to prevent entry by climbing rodents. Snap traps were maintained within exclosures to ensure they remained secure. Three $0.5-\mathrm{m}^{2}$ subplots were randomly located within each rodent exclosure and nearby rodent exclosure control. The vegetation within the subplots was killed in early July using the broadspectrum, low-persistence herbicide Roundup (Mon- santo, St. Louis, Missouri, USA) and plots were hoed to mineral soil in late July. As part of a larger study, subplots were assigned to one of three treatments: native seed addition, exotic seed addition, or control subplots where no seeds were added. Seed addition subplots received either 20 species of native plant seeds or 19 species of exotic plant seeds. From these species, we evaluated all the native and exotic asters with seeds that we deemed large enough for P. maniculatus to forage on in the field (seed mass $>0.0004 \mathrm{~g}$ based on our experience with laboratory trials). All seeds were collected locally in 2009 and added in late August 2009 by spreading them evenly over the subplots and gently patting them into the surface soil so that seeds were anchored but visible. To allow for differences in seed size, the quantity of seeds added to each plot was stratified by seed mass, with 50 seeds added for seeds $>0.006 \mathrm{~g}, 100$ seeds added for seeds $\leq 0.006 \mathrm{~g}$ and $>0.001 \mathrm{~g}$, and 175 seeds added for seeds $\leq 0.001 \mathrm{~g}$ (Appendix). We censused all seed addition plots 3-4 times from May through July and recorded seedling emergence, survival, and establishment. We report only on establishment defined as the number of seedlings still alive by the onset of summer senescence in July.

Based on eight years of trapping (Maron et al. 2010), $P$. maniculatus is the primary seed predator in this system. Herbivorous montane voles (Microtus montanus) and Columbian ground squirrels (Spermophilus columbianus) were the only two other small-mammal species captured from 2009 to 2010. Although voles and ground squirrels can consume seeds, ground squirrels were hibernating when seeds were out, and previous analyses of vole and mouse abundance in relation to seed removal from seed depots indicates mice and not voles are responsible for seed predation (Maron and Pearson, in press). Exclosures did not preclude access by ground-foraging birds or invertebrates, but seed trays placed within rodent exclosures show little seed removal by birds or insects (J. L. Maron and D. E. Pearson, unpublished data).

\section{Analyses}

Laboratory feeding trial results were analyzed using compositional analyses in $\mathrm{R}$ (function compana in package edehabitat, version 1.8.3, R Development Core Team [2006]). Compositional analyses is a multivariate approach traditionally applied to habitat selection analyses to address the lack of independence among habitat proportions (Aebischer et al. 1993); the method can similarly be applied to address the lack of independence between samples in feeding trial experiments (see Woods 2009). To perform compositional analysis, the unit sum constraints on the observations are removed by taking log-ratio transformations of the observations within feeding trials such that correlations between food types across trials are preserved (Aitchison 1986). Then, standard MANOVA can be performed and assessed using the statistic $\lambda$, the ratio of the determi- 

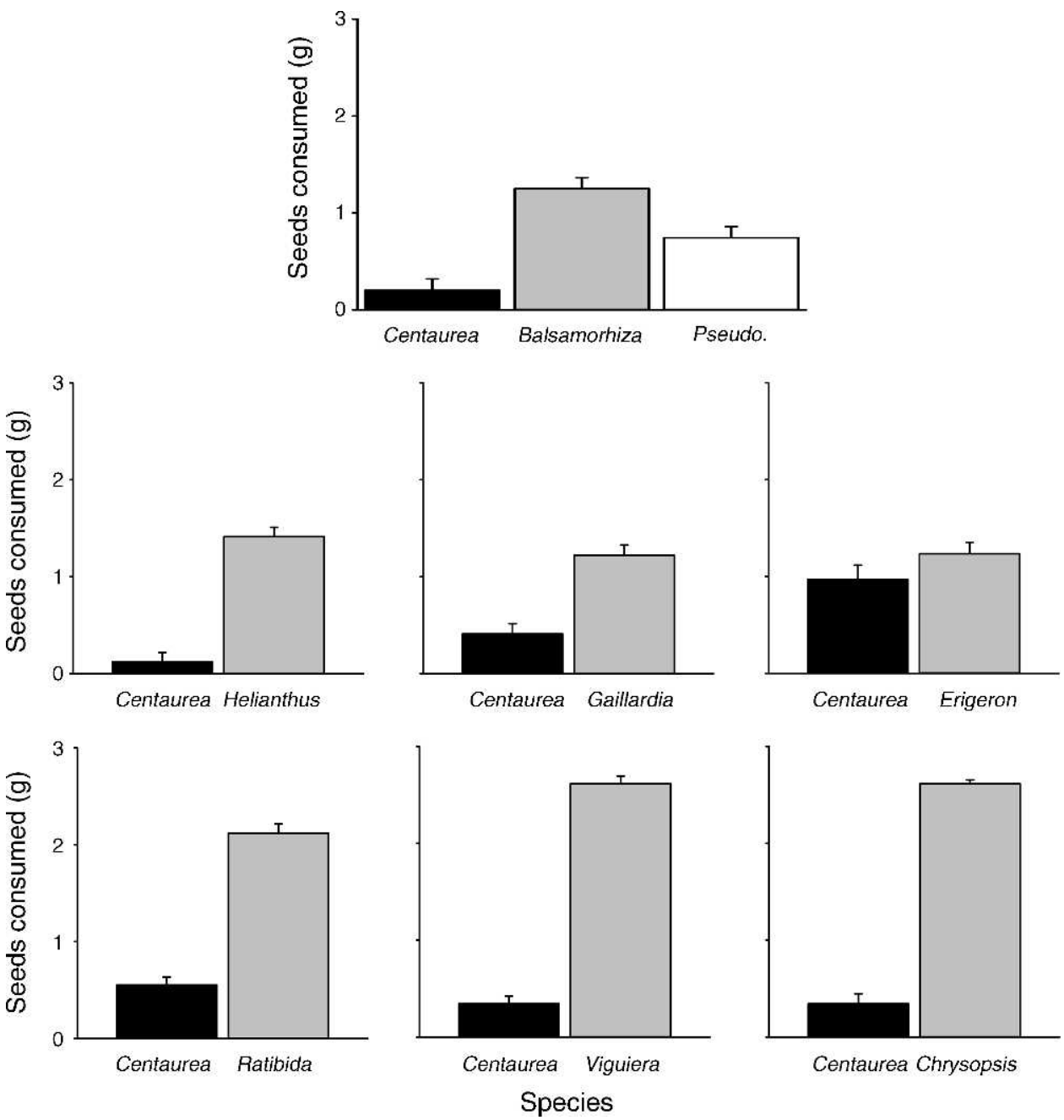

FIG. 1. Feeding trial results comparing seed consumption by the deer mouse, Peromyscus maniculatus, between the strongly invasive aster Centaurea stoebe and eight native asters. Data are raw means + SE. Sample sizes are given in Table 1. Pseudo. represents Pseudoroegneria spicata, the dominant native grass. Complete scientific names are in Table 1.

nants of the hypothesized and reduced model residual sums of squares and cross-product matrices (Aebischer et al. 1993). We analyzed seed addition results using mixed linear models (PROC MIXED; SAS Institute 2003) with the number of established young plants as the dependent variable, plant origin/invader status (native, exotic strong invader, exotic weak invader), mouse access, and their interaction as fixed factors, and site as a random factor. Contrast statements were used to focus on the invader status $\times$ mouse access interaction in order to specifically compare the relative response of the strong invader vs. the weak invaders and the strong invader vs. the natives. Number of seeds added was included as a covariate to standardize for seed size differences, since number of seeds added differed by species, as described above. However, the seed number covariate was not significant $(P=0.55)$ and it did not improve the AIC for the model, so the covariate was not included in the final analysis. We compared absolute recruitment for individual species by rodent exclusion treatment using generalized mixed linear models, with the number of established young plants as the dependent variable, mouse access as a fixed factor and site as a random factor. We used linear regression to examine the relationship between seed mass and the average change in recruitment when rodents were excluded from seeds (referred to as the release effect).

\section{RESUlts \\ Laboratory feeding trials}

In laboratory feeding trials, $P$. maniculatus consumed fewer seeds of $C$. stoebe than any other exotic or native species with which it was compared (Figs. 1 and 2, Table 1). Compositional analysis indicated that seed consumption in the three-way trial differed significantly overall among $C$. stoebe and the two native species $(\lambda=0.59$, df $=2, P=0.005)$. The ranking profile for this test 


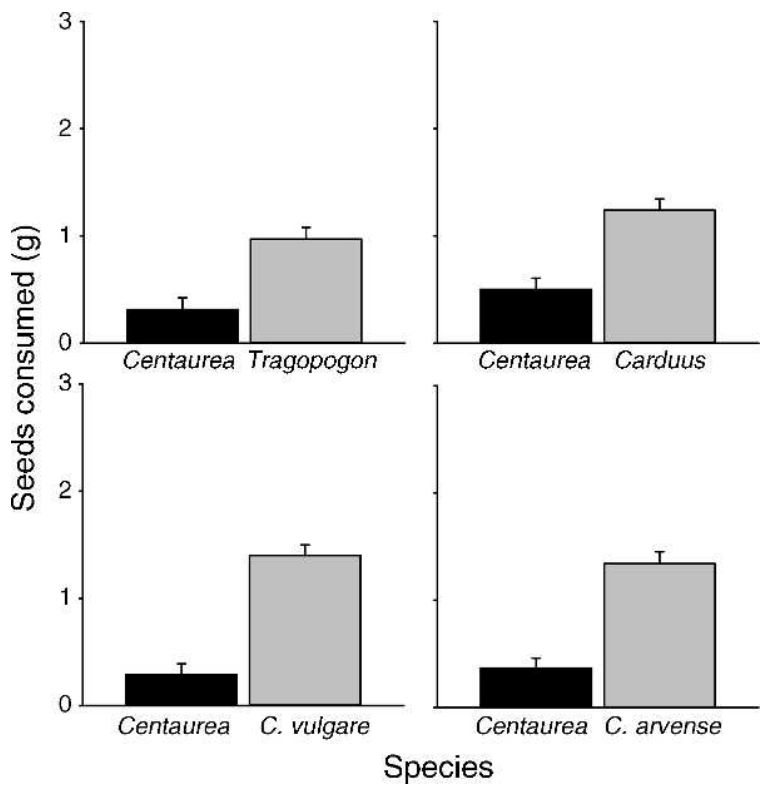

FIG. 2. Feeding trial results comparing seed consumption between the strongly invasive aster Centaurea stoebe and four weakly invasive asters. Data are raw means + SE. Sample sizes are given in Table 1. Cirsium is represented by C. vulgare and $C$. arvense. Complete scientific names are in Table 1.

specifically indicated that mice consumed significantly more B. sagittata than $C$. stoebe, and more $P$. spicatum than $C$. stoebe, but consumption of B. sagittata and $P$. spicatum did not differ significantly (95\% confidence intervals overlapped). In the two-way trials, all other species were significantly preferred by $P$. maniculatus over C. stoebe (Table 1) except for Erigeron caespitosus, which was marginally significant $(P=0.06)$. Results for $T$. dubius were heavily influenced by a single extreme outlier point resulting from one mouse that ate a few $C$. stoebe seeds and no T. dubius seeds. Due to the unit-sum constraint (Aebischer et al. 1993), compositional analysis is highly sensitive to extreme outliers, such as when total consumption is of only one item, but that item itself is little consumed. Because this outlier was not only different from the other replicate trials we ran as part of this experiment, but also extremely divergent from many past feeding trials that we have performed (both in the laboratory and field), where we have consistently found that deer mice prefer T. dubius over C. stoebe and other species (J. L. Maron and D. E. Pearson, unpublished data), we dropped the outlier data point. Analyses without the outlier revealed a highly significant preference by deer mice for $T$. dubius over C. stoebe $(\lambda=0.36$, $\mathrm{df}=1, P<0.01)$.

\section{Seed addition experiments}

None of the sown species recruited into control plots where no seeds were added. We also found no $B$. sagittata seedlings in any seed addition plots; however, all other sown species exhibited some recruitment into experimental plots. We found a marginally significant interaction between invader status (weak vs. strong) and rodent exclusion $\left(F_{1,114}=3.85, P=0.05\right)$, indicating that weak invaders experienced greater release from rodent exclusion than did $C$. stoebe. There was a strong trend for the two natives ( $G$. aristida and $H$. villosa) to increase in the absence of rodents, but the interaction between plant status (strong invader vs. natives) and rodent exclusion was not significant $\left(F_{1,114}=1.44, P=0.23\right)$. Establishment of individual species tended to be higher in rodent exclusion plots compared to rodent-exclusion controls for all species except $C$. stoebe (Fig. 3), but this was significant only for $T$. dubius (all other species $P>$ $0.05 ; T$. dubius $\left.F_{1,17}=9, P<0.01\right)$. Seed mass did not predict how strongly rodent exclusion positively influenced recruitment of species when $C$. stoebe was included $\left(F_{1,4}=4.33, P=0.11\right)$. However, when we excluded $C$. stoebe from the analysis, seed mass significantly predicted $81 \%$ of the variation in how species responded to rodent exclusion $\left(F_{1,3}=12.33, P=\right.$ $\left.0.04 ; r^{2}=0.81\right)$. In addition, seed mass of $C$. stoebe fell well outside the $95 \%$ CI calculated for this regression line, indicating that the relationship between seed mass and impacts of granivory on recruitment was clearly different for $C$. stoebe compared to all other species. Our regression model predicts that a species with seed mass comparable to $C$. stoebe should experience much greater release from rodent seed predation than what we observed in our rodent exclosures, suggesting that

TABLE 1. Compositional analysis results for two-way feeding trials with the deer mouse, Peromyscus maniculatus, comparing each species with Centaurea stoebe.

\begin{tabular}{lcccr}
\hline \hline \multicolumn{1}{c}{ Species } & No. trials & $\lambda$ & df & \multicolumn{1}{c}{$P$} \\
\hline Tragopogon dubius & 14 & 0.36 & 1 & $<0.01$ \\
Carduus nutans & 10 & 0.38 & 1 & 0.01 \\
Cirsium vulgare & 10 & 0.30 & 1 & 0.01 \\
Cirsium arvense & 5 & 0.53 & 1 & $<0.01$ \\
Gaillardia aristata & 10 & 0.30 & 1 & $<0.01$ \\
Helianthus maximiliana & 10 & 0.11 & 1 & $<0.01$ \\
Ratibida columnifera & 12 & 0.16 & 1 & $<0.01$ \\
Viguiera mulitiflora & 10 & 0.08 & 1 & 0.01 \\
Chrysopsis villosa & 7 & 0.36 & 1 & 0.06 \\
Erigeron caespitosus & 10 & 0.70 & 1 &
\end{tabular}

Note: The reported statistic, $\lambda$, is comparable to a Wilks' lambda in MANOVA. 


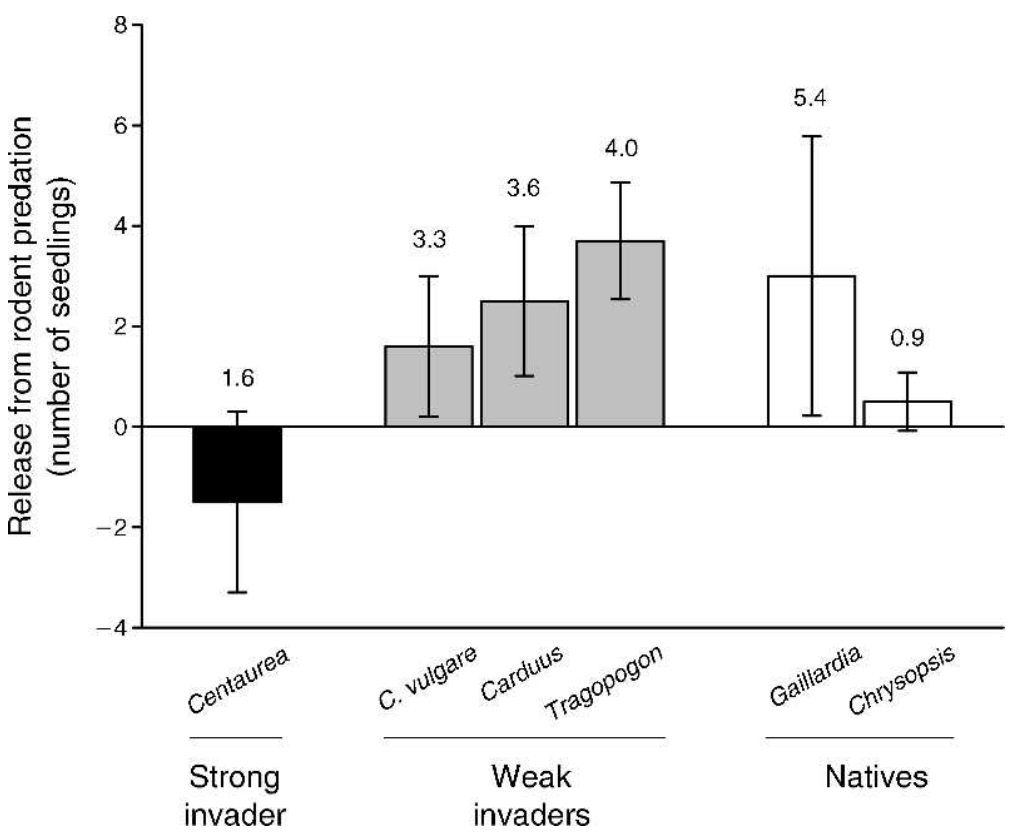

FIG. 3. Effects of rodent exclusion on seedling recruitment measured as release from seed predation (number of seedlings emerging in rodent exclusion plots minus number in paired control plots) for the strong invader Centaurea stoebe, three weak invaders, and two natives in the Asteraceae. The third native, B. sagittata, failed to emerge. There were 10 pairs of rodent exclusion and control plots spread across the Blackfoot Valley. The values above the bars indicate the mean absolute numbers of seedlings establishing per plot inside the rodent exclosures. Error bars represent means \pm SE. Complete scientific names are in Table 1.

factors other than seed mass explain the lack of response by $C$. stoebe to rodent exclusion.

\section{DisCUSSION}

Efforts to understand the role of biotic resistance in affecting exotic plant invasions have mostly focused on plant competition (Levine et al. 2004). Yet, as our results indicate, native generalist seed predators may influence patterns of invasion in important ways, as well. We found that the seeds of native asters, as well as exotic asters that generally occur at low abundance in western Montana, were readily consumed by $P$. maniculatus in laboratory feeding trials. In contrast, seeds of the strong invader $C$. stoebe were avoided. In the field, seed mass largely explained the degree to which natives and weak invaders recruited after experimental rodent exclusion. Yet recruitment of $C$. stoebe in the field was unaffected by rodent granivory despite the fact that its relatively large seed size should make it a target for predation. These results also underscore the notion that the abundance of weak invaders may be controlled by processes similar to those that influence native species, whereas strong invaders appear to operate by different rules (sensu Ortega and Pearson 2005).

In laboratory feeding trials, the eight native and four weakly invasive exotics were all preferred by $P$. maniculatus over C. stoebe. Moreover, although $C$. stoebe seeds were sampled by virtually all mice, very few seeds were consumed (only $5 \%$ of 98 test mice consumed one-third or more of the of the available C. stoebe seeds). The fact that $C$. stoebe was avoided even when it was contrasted with comparably sized or substantially smaller asters suggests that it was somehow less appealing to the mice. Centaurea stoebe's seeds do not possess physical defenses such as spines, they do not have a large pappus, which could increase handling time, and seeds do not appear to have a particularly hard seed coat, since mice readily open the seeds when sampling them. Thus, superficially, C. stoebe seeds appear quite conducive to mouse consumption. In contrast, some of the comparably sized and smaller natives such as $G$. aristida and E. caespitosus have large pappuses and small endosperms and embryos, relative to the external seed structures that would increase handling time per unit tissue consumed. We did not evaluate the nutritional content of the seeds, but it is unlikely that poor nutritional value alone could explain the strong avoidance of $C$. stoebe relative to all 12 other species we tested. It also seems unlikely given that mice preferred species such as $R$. columnifera, V. multiflora, and $C$. villosa over $C$. stoebe, despite the fact that seeds of these species are $53 \%, 59 \%$, and $94 \%$ smaller, respectively, than $C$. stoebe. Others have shown that $C$. stoebe experiences reduced herbivory compared with a range of weak invaders, presumably due to secondary defense compounds such as cnicin (Cappuccino and Carpenter 2005, Cappuccino and Arnason 2006). Centaurea stoebe seeds could possess chemical compounds that deter mice, but we did not evaluate the chemical composition of the seeds. 


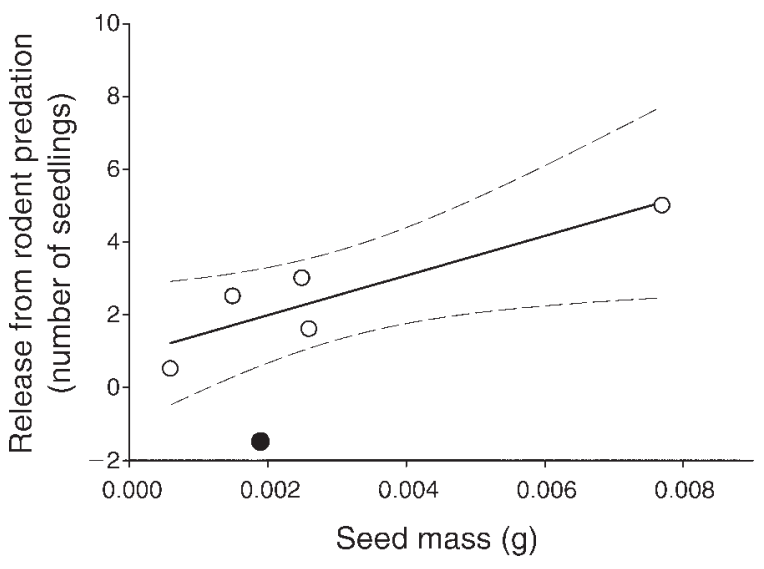

FIG. 4. Relationship between seed mass and the difference in mean number of seedlings established as of July in vs. outside of rodent exclosures (i.e., "release") for six native and exotic aster species. The solid circle represents C. stoebe. The center straight line is the linear regression fitting the data using all species except $C$. stoebe, which is an outlier. The outer lines represent the $95 \%$ CI for the regression.

Our field experiment examined how rodent postdispersal seed predation might influence seedling recruitment for a suite of asters that vary in seed size, origin, and abundance in western Montana. Although herbivorous voles and ground squirrels are present on our sites, our repeated checks on emerging and establishing seedlings provided little evidence of herbivore-induced mortality. Additionally, seed offerings placed within rodent exclosures across the study sites gave little evidence of bird or ant foraging. Hence, we attribute rodent exclusion effects on establishment primarily to seed predation by $P$. maniculatus. We found that these mice suppressed recruitment of weak invaders relative to C. stoebe. Native plant recruitment also tended to be suppressed by seed predation relative to $C$. stoebe, but not significantly so. This could have been due to the low emergence of natives such as $C$. villosa and B. sagittata. We know from previous work that $B$. sagittata suffers from heavy postdispersal seed predation, and protecting its seeds from rodents substantially enhances seedling recruitment (Pearson and Callaway 2008). It may be that the overall poor recruitment of $B$. sagittata was due to low viability of seeds we added to plots. Of all the native and weakly invasive asters tested, only $T$. dubius showed an absolute increase in recruitment due to rodent exclusion, although others trended in this direction. Previous studies examining impacts of postdispersal seed predation found that rodent seed removal from petri dishes was very high for $T$. dubius, while removal of $C$. stoebe seeds in the same experiment was very low (Mittlebach and Gross 1984). Reader (1993) showed that high predation by rodent granivores on $T$. dubius seeds resulted in substantial declines in recruitment in Ontario old fields. While many studies show that rodents tend to select larger seeds (Mittlebach and Gross 1984, Brown and Heske 1990, Reader 1993,
Blaney and Kotanen 2001, Pearson and Callaway 2008), Carrillo-Gavilán et al. (2010) found that smaller exotic Pinus seeds were removed more often than larger ones when only rodents had access to seeds. However, the pine seeds they studied represented larger seed sizes than the herbaceous plants we used. In fact, the two largest species of seeds they studied, which appeared to determine their rodent results, were 60-80 times larger than the seeds of our largest species, and may have exceeded optimal seed sizes for selection by their granivorous rodents.

We found that seed size explained $81 \%$ of the variation in how rodent exclusion influenced recruitment for native and weakly invasive asters. However, $C$. stoebe was an outlier in this regard. That is, although its seed mass predicts that $C$. stoebe should be strongly suppressed by rodent predation, this was not the case (Fig. 4), a result consistent with our laboratory feeding trials. In restricting our study to asters, we were limited to examining recruitment effects for only six species. Hence, the regression results should be treated with caution. Nonetheless, C. stoebe was clearly large enough to be readily consumed by mice, but mice appeared to avoid this seed in both the laboratory and the field. Notably, $P$. maniculatus numbers were higher than normal at $\sim 13$ mice/ha in fall 2009 (Maron et al. 2010), so foraging rates of mice may have been somewhat higher than normal in our system during this sampling period. These $P$. maniculatus densities are low to average compared to more arid grasslands in this region (Pearson and Callaway 2006, Pearson and Fletcher 2008).

One fruitful approach to understanding biological invasions is examining the factors that lead to differences in abundance between natives and different classes of exotics (e.g., Mitchell and Power 2003, Cappuccino and Carpenter 2005, Ortega and Pearson 2005, van Kleunen et al. 2010). Some evidence suggests that highly invasive exotics experience greater release from pathogens relative to weak invaders, and weak invaders experience greater biotic resistance from accumulated pathogens in recipient communities relative to strong invaders (Mitchell and Power 2003). Strong invaders also may experience stronger positive and weaker negative soil feedbacks relative to native species or weak invaders (Callaway et al. 2004). Similarly, herbivore attack rates are sometimes higher on weakly invasive species relative to more strongly invasive exotics (Cappuccino and Carpenter 2005). Differences in herbivore attack rates on strong vs. weak invaders has been attributed to the degree of novelty in plant secondary compounds relative to the native systems (Cappuccino and Arnason 2006), which could explain why herbivory does not differ between exotic and native plants in some phylogenetically controlled comparisons (Agrawal and Kotanen 2003). Collectively, these studies, along with ours, suggest that biotic filters created by 
native pathogens, herbivores, and granivores help explain variation in exotic invader success.

Looking beyond the question of how native consumers may influence establishment and ultimate abundance of exotics, remarkably little is known about how variation in seed traits among species influences broader patterns of recruitment in native systems where postdispersal seed predation by rodents is frequent. We know that recruitment of large-seeded species can be reduced by rodent seed predation (Davidson et al. 1984, Brown and Heske 1990, Howe and Brown 2000, Maron and Kauffman 2006, Pearson and Callaway 2008, Bricker et al. 2010, Zwolak et al. 2010). However, most studies that have examined how seed traits affect seed removal by rodents have been very short term and fail to link seed removal rates to recruitment (e.g., Blaney and Kotanen 2001, Shahid et al. 2009, Carrillo-Gavilan et al. 2010). Compensatory processes such as density-dependent seedling mortality can decouple strong seed predation from subsequent impacts on seedling establishment (Crawley 1992). Moreover, short-term consumer seed preferences may not reflect long-term patterns of seed consumption because changing background conditions can affect energetic needs of the consumer, alter availability of alternative food resources, and change seed apparency in ways that affect consumer foraging decisions. For example, two studies pairing seed offering experiments with seedling recruitment experiments (Pearson and Callaway 2008, Zwolak et al. 2010) both showed that rodents removed larger seeds from trays, but this result is translated to differential effects on recruitment in only one of these studies. Presumably, once the larger-seeded species was reduced sufficiently, the smaller-seeded species was targeted with equal intensity and drawn down to similar levels before seeds germinated (Zwolak et al. 2010). In other experiments in this system, we found that patterns of short-term seed removal from trays were not reflected in longer-term seed removal experiments where seeds were placed on the ground (Maron and Pearson, in press).

Even studies that have taken the extra step to experimentally examine effects of rodent seed predation on plant recruitment have typically only focused on one or a few species (Maron and Kauffman 2006, Pearson and Callaway 2008, Bricker et al. 2010, Zwolak et al. 2010). These studies have been informative as to rodent impacts on the abundance of particular species, and they strongly suggest that postdispersal seed predation has the potential to be an important community filter. Yet remarkably few studies have examined how seed predation may affect plant community assembly (but see Brown and Heske 1990, Howe and Brown 2000). What we need at this juncture are longer-term, community-level studies that quantify the effects of seed traits on seed predation and plant recruitment across a range of species. One notable step in this direction was offered by Reader (1993), who examined seed predation effects across a dozen old-field species representing a range of seed sizes. Consistent with our results, he found that the degree to which recruitment increased in the absence of seed predation scaled positively with seed size. Our study and Reader's suggest that establishing the linkages between seed attributes and postdispersal seed predation may greatly expand our understandings of plant community assembly. Future studies that explore how traits beyond seed size such as defense, nutrition, apparency, and other attributes, influence vulnerability to postdispersal seed predation will be valuable in shedding light on how seed predation affects native plant community assembly and how biotic resistance affects exotic species invasions.

\section{ACKNOWLEDGMENTS}

We thank Brian Connolly, Yvette Ortega, and anonymous reviewers for valuable feedback on the manuscript. Yvette Ortega advised on the SAS analysis, and L. Scott Baggett consulted on the compositional analysis. We thank William Brann, Jessica Brewer, Carl Brown, Warren Hansen, Winslow Hansen, Chris Henderson, Leslie Parker, Teal Potter, Samantha Sears, Anna Semple, Giles Thelen, and Matthew Wegener for field and laboratory help. This work was supported by NSF DEB-0915409 and USDA CSREES 2005-35101-16040 grants to John Maron and Dean Pearson and NSF DEB-0614406 to John Maron and Ragan Callaway and support from the Rocky Mountain Research Station to Ragan Callaway, Dean Pearson, and John Maron.

\section{Literature Cited}

Aebischer, N. J., P. A. Robertson, and R. E. Kenward. 1993. Compositional analysis of habitat use from animal radiotracking data. Ecology 74:1313-1325.

Agrawal, A. A., and P. M. Kotanen. 2003. Herbivores and the success of exotic plants: a phylogenetically controlled approach. Ecology Letters 6:712-715.

Aitchison, J. 1986. The statistical analysis of compositional data. Chapman and Hall, New York, New York, USA.

Alba-Lynn, C., and S. Henk. 2010. Potential for ants and vertebrate predators to shape seed-dispersal dynamics of the invasive thistles Cirsium arvense and Carduus nutans in their introduced range (North America). Plant Ecology 210:291301.

Blaney, C. S., and P. M. Kotanen. 2001. Post-dispersal losses to seed predators: an experimental comparison of native and exotic old field plants. Canadian Journal of Botany 79:284292.

Bricker, M., D. Pearson, and J. L. Maron. 2010. Smallmammal seed predation limits the recruitment and abundance of two perennial grassland forbs. Ecology 91:85-92.

Brown, J. H., and E. J. Heske. 1990. Control of a desertgrassland transition by a keystone rodent guild. Science 250:1705-1707.

Callaway, R. M., G. C. Thelen, A. Rodriguez, and W. E. Holben. 2004. Release from inhibitory soil biota in Europe may promote exotic plant invasion in North America. Nature 427:731-733.

Cappuccino, N., and J. T. Arnason. 2006. Novel chemistry of invasive exotic plants. Biology Letters 2:189-193.

Cappuccino, N., and D. Carpenter. 2005. Invasive exotic plants suffer less herbivory than non-invasive exotic plants. Biology Letters 1:435-438.

Carrillo-Gavilán, M. A., H. Lalague, and M. Vilá. 2010. Comparing seed removal of 16 pine species differing in invasiveness. Biological Invasions 12:2233-2242. 
Clark, C. J., J. R. Poulsen, D. J. Levey, and C. W. Osenberg. 2007. Are plant populations seed limited? A critique and analysis of seed addition experiments. American Naturalist 170:128-142.

Crawley, M. J. 1992. Seed predators and plant population dynamics. Pages 157-192 in M. Fenner, editor. Seeds: the ecology of regeneration in plant communities. CAB International, Wallingford, Connecticut, USA.

Dangremond, E. M., E. A. Pardini, and T. M. Knight. 2010. Apparent competition with an invasive plant hastens the extinction of an endangered lupine. Ecology 91:2261-2271.

Darwin, C. 1859 . On the origin of species by means of natural selection, or the preservation of favoured races in the struggle for life. John Murray, London, UK.

Davidson, D. W., R. S. Inouye, and J. H. Brown. 1984. Granivory in a desert ecosystem: experimental evidence for indirect facilitation of ants by rodents. Ecology 65:17801786.

Elton, C. 1958. The ecology of invasions by animals and plants. University of Chicago Press, Chicago, Illinois, USA.

Howe, H. F., and J. S. Brown. 2000. Early effects of rodent granivory on experimental forb communities. Ecological Applications 10:917-924.

Howe, H. F., B. Zorn-Arnold, A. Sullivan, and J. S. Brown. 2006. Massive and distinctive effects of meadow voles on grassland vegetation. Ecology 87:3007-3013.

Keane, R. M., and M. J. Crawley. 2002. Exotic plant invasions and the enemy release hypothesis. Trends in Ecology and Evolution 4:164-170.

Levine, J. M., P. B. Adler, and S. G. Yelenik. 2004. A metaanalysis of biotic resistance to exotic plant invasions. Ecology Letters 7:975-989.

Mack, R. N. 1996. Biotic barriers to plant naturalization. Pages 39-46 in V. C. Moran and J. H. Hoffmann, editors. Proceedings of the IX International Symposium on Biological Control of Weeds. University of Cape Town, Stellenbosch, South Africa.

Maron, J. L., and M. J. Kauffman. 2006. Habitat-specific impacts of multiple consumers on plant population dynamics. Ecology 87:113-124.

Maron, J. L., and D. E. Pearson. In press. Vertebrate predators have minimal cascading effects on plant production or seed predation in an intact grassland ecosystem. Ecology Letters.

Maron, J. L., D. E. Pearson, and R. Fletcher, Jr. 2010. Counter-intuitive effects of large-scale predator removal on a mid-latitude rodent community. Ecology 91:3719-3728.

Maron, J. L., and M. Vilá. 2001. When do herbivores affect plant invasion? Evidence for the natural enemies and biotic resistance hypotheses. Oikos 95:361-373.

Mitchell, C. E., and A. G. Power. 2003. Release of invasive plants from fungal and viral pathogens. Nature 42:625-627.

Mittlebach, G. G., and K. L. Gross. 1984. Experimental studies of seed predation in old-fields. Oecologia 65:7-13.

Nunez, M. A., D. Simberloff, and M. A. Relva. 2008. Seed predation as a barrier to alien conifer invasions. Biological Invasions 10:1389-1398.

Orrock, J. L., M. S. Witter, and O. J. Reichman. 2008. Apparent competition with an exotic plant reduces native plant establishment. Ecology 89:1168-1174.
Ortega, Y. K., and D. E. Pearson. 2005. Strong versus weak invaders of natural plant communities: distinguishing invasibility from impact. Ecological Applications 15:651-661.

Ostfeld, R. S., R. H. Manson, and C. D. Canham. 1997. Effects of rodents on survival of tree seeds and seedlings in invading old fields. Ecology 78:1531-1542.

Parker, J. D., D. E. Burkepile, and M. E. Hay. 2006. Opposing effects of native and exotic herbivores on plant invasions. Science 311:1459-1461.

Pearson, D. E., and R. M. Callaway. 2006. Biological control agents elevate hantavirus by subsidizing mice. Ecology Letters 9:443-450.

Pearson, D. E., and R. M. Callaway. 2008. Weed biocontrol insects reduce native plant recruitment through second-order apparent competition. Ecological Applications 18:1489-1500.

Pearson, D. E., and R. J. Fletcher, Jr. 2008. Mitigating exotic impacts: restoring native deer mouse populations elevated by an exotic food subsidy. Ecological Applications 18:321-334.

R Development Core Team. 2006. R: a language and environment for statistical computing. R Foundation for Statistical Computing, Vienna, Austria. 〈http://www. R-project.org $\rangle$

Reader, R. J. 1993. Control of seedling emergence by ground cover and seed predation in relation to seed size for some oldfield species. Journal of Ecology 81:169-175.

SAS Institute. 2003. SAS/STAT user's guide, Version 8. SAS Institute, Cary, North Carolina, USA.

Schaffner, U., W. M. Ridenour, V. C. Wolf, T. Bassett, C. Müller, H. Müller-Schärer, S. Sutherland, C. J. Lortie, and R. M. Callaway. 2011. Plant invasions, generalist herbivores, and novel defense weapons. Ecology 92:829-835.

Shahid, A., D. E. Garneau, and T. S. McCay. 2009. Selection of seeds of common native and non-native plants by granivorous rodents in the northeastern United States. American Midland Naturalist 162:207-212.

Sheley, R. L., J. S. Jacobs, and M. F. Carpinelli. 1998. Distribution, biology, and management of diffuse knapweed (Centaurea diffusa) and spotted knapweed (Centaurea maculosa). Weed Technology 12:353-362.

Swope, S. M., and I. M. Parker. 2010. Widespread seed limitation affects plant density but not population trajectory in the invasive plant Centaurea solstitialis. Oecologia 164:117-128.

van Kleunen, M., W. Dawson, D. Schlaepfer, J. M. Jeschke, and M. Fischer. 2010. Are invaders different? A conceptual framework of comparative approaches for assessing determinants of invasiveness. Ecology Letters 13:947-958.

Vilá, M., and I. Gimeno. 2003. Seed predation of two alien Opuntia species invading Mediterranean communities. Plant Ecology 167:1-8.

Williamson, M. H., and A. Fitter. 1996. The characters of successful invaders. Biological Conservation 78:163-170.

Wilson, D. E., and S. Ruff. 1999. The Smithsonian book of North American mammals. Smithsonian Institution Press, Washington, D.C., USA.

Woods, B. C. 2009. Using multivariate techniques to determine if yellow-bellied marmots feed selectively. Ethology, Ecology and Evolution 21:261-276.

Zwolak, R., D. E. Pearson, Y. K. Ortega, and E. E. Crone. 2010. Fire and mice: Seed predation moderates fire's influence on conifer recruitment. Ecology 91:1124-1131.

\section{APPENDIX}

Plant species used in laboratory feeding trials and field seed addition experiments. (Ecological Archives E092-149-A1). 